\title{
Performance evaluation of different configurations of system with DSTATCOM using proposed Icos $\phi$ technique
}

\author{
Atma Ram, Parsh Ram Sharma, Rajesh Kumar Ahuja \\ Department of Electrical Engineering, Faculty in Engineering and Technology, J. C. Bose University of Science and Technology, \\ YMCA, Faridabad, India
}

\begin{abstract}
Article Info
Article history:

Received Jan 17, 2021

Revised Nov 8, 2021

Accepted Nov 27, 2021

ABSTRACT

The proposed I $\cos \phi$ control technique has been applied for power quality improvement using different configurations of system with distribution static compensator (DSTATCOM). Modeling, design and control of DSTATCOM are analyzed in detail. Three phase reference current are extracted with this technique. The proposed technique has been used for power factor enhancement, voltage regulation, harmonic suppression and load balancing under dynamic condition with non-linear load. The proposed control is very effective for three different configurations of system with DSTATCOM for power quality improvement. Results for each configuration of system with DSTATCOM are simulated using MATLAB/Simulink sim power tool box. For teaching the power quality course, these can also be helpful.
\end{abstract}

Keywords:
DSTATCOM
Icos $\phi$ technique
Power factor correction
Power quality
Simulation

Simulation

\section{Corresponding Author:}

Atma Ram

Department of Electrical Engineering, Faculty in Engineering and Technology

J. C. Bose University of Science and Technology, YMCA

Faridabad, Haryana 121006, India

Email: atma.ram12@gmail.com, atmaram@jcboseust.ac.in
This is an open access article under the CC BY-SA license.

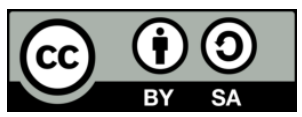

\section{INTRODUCTION}

At the present the poor power quality is the major problems at load end in distribution system [1]-[4]. Most of linear loads are lagging power factor and non-linear loads which creates power quality problems, for example converter based on power electronics used in uninterruptible power supply (UPS), variable speed alternating current (AC) and direct current (DC) drives, television (TV), domestic load, battery charger. Reactive power is drawn by this type of load and generates harmonic problems in distribution system, which creates distortion in source and reduces load side voltage. For enhancement of these kinds of problems distribution static compensator (DSTATCOM) can be used at point of common coupling (PCC). Various configuration of DSTATCOM for enhancement of power quality are presented in literature for example, 3-legs voltage source converter (VSC) [1], three legs VSC with spilt capacitor [3], four legs based VSC [4], and H-bridge using star/delta transformer [5], and three legs VSC using zig-zag transformer [6]-[10].

Various control methods are presented literature for control of DSTATCOM and computation of supply reference current such as proportional integral (PI) controller based instantaneous reactive power theory (IRPT), instantaneous-symmetrical component (ISC), neural network controller and synchronous reference frame theory (SRFT) [1]-[4]. Mechanism based on Icos $\phi$ control technique has been described power factor improvement using DSTATCOM in [11]-[13]. The 3-phases 4-wires distribution system with zig-zag transformer and DSTATCOM are presented in [14] using MATLAB. DSTATCOM with 3-different system topologies have been implemented using synchronous reference frame theory (SRFT) technique [15]. Self tuned filter based IRPT technique for enhancement of power quality has been reported in [16]. Different 
topologies with DSTATCOM for mitigation of power quality issues in distribution system have been developed and implemented [17]. LMS based control technique is developed for reference current extraction and these currents are subtracted from real supply current for estimation of firing pulses for DSTATCOM [18]. Neural network based on back propagation in $\operatorname{Icos} \phi$ technique is presented for 3-phases 4-wires DSTATCOM for reduction of power quality related problems and active/reactive components of weight are estimated smoothly for reference current generation with this technique [19]. The comparison of star/delta and zig/zag transformer based DSTATCOM with unit templates based control technique has been presented in [20]. Fuel cell integration in distribution system through DSTATCOM for power quality improvement using Icos $\phi$ technique for reference current extraction has been described [21]. The photovoltaic supported DSTATCOM in distribution system has been implemented with Icos $\phi$ control technique for power quality improvement [22]. Comparisons of phase locked loop (PLL) based control mechanism with DSTATCOM have been implemented for mitigation of load created power quality problems [23]. The quasi newton least mean fourth based control mechanism has been described with DSTATCOM and used mitigation of power quality problems in PSMG which is used as wind generation unit [24]. The optimal step least mean square (LMS) based control technique with DSTATCOM in three phase distribution system has been presented for harmonic suppression and reactive power compensation [25]. Least mean square-least mean forth (LMSLMF) based control technique for DSTATCOM in power factor correction (PFC) and zero voltage regulation (ZVR) mode operation has been presented for mitigation of power quality problems [26]. Adaptive volterra second-order filter (AVSF) based control algorithm with DSTATCOM has been presented for harmonic suppression and compensation of reactive power in distribution system [27].

The technique based on hopfield neural network (HNN) for DSTATCOM has been developed for improvement of power quality in terms of power factor improvement, source side harmonic suppression and load balancing in a distribution system [28]. The SRFT technique using advance phase-locked loop (PLL) for $\mathrm{H}$ bridge multilevel inverter based DSTATCOM has been presented for mitigation of power qualities issues [29]. The adaptive control using Kernel based training in Icos $\phi$ technique used for retained the direct and quadrature component of load currents, has been proposed for fuel cell based DSTATCOM for power qualities problems improvement [30]. Different configurations of systems with DSTATCOM are described using proposed Icos $\phi$ technique in MATLAB. DSTATCOM performances are studied in terms of supply current harmonics elimination, load balancing and reactive power compensation under non-linear varying load.

\section{THREE DIFFERENT CONFIGURATIONS OF SYSTEM WITH DSTATCOM}

Many configurations of system are exists with DSTATCOM. Out of many configurations of system three are selected and these are;

- Configuration1 of system with DSTATCOM using source side rectifier is presented in Figure 1 and implemented for power quality improvement with proposed I $\cos \phi$ technique for PFC mode of DSTATCOM operation for harmonic suppression, load balancing, reactive power compensation and voltage regulation.

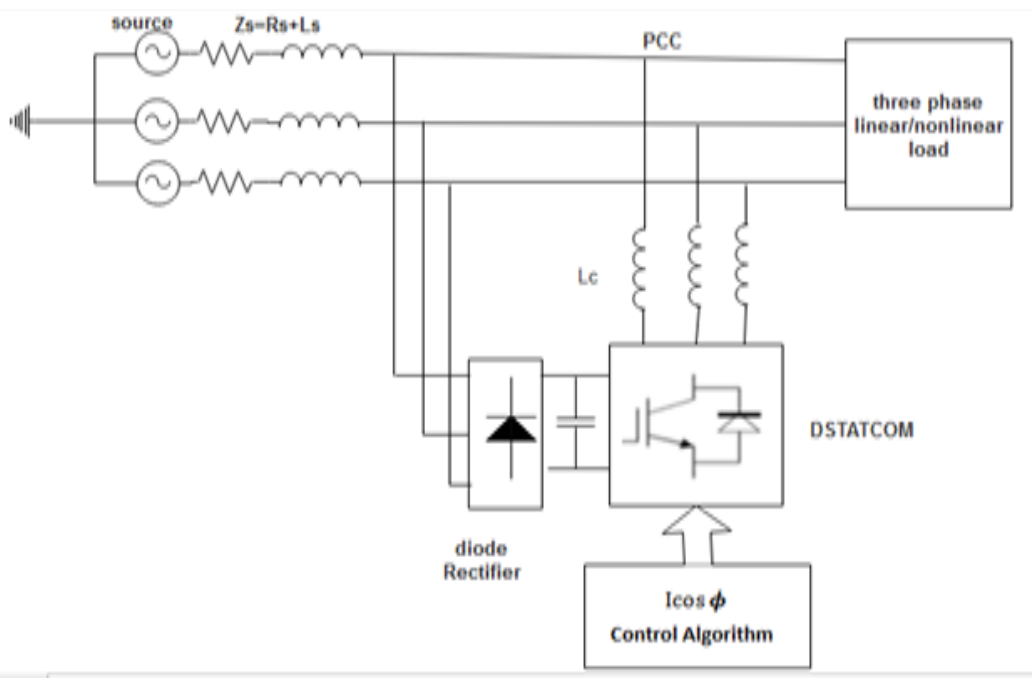

Figure 1. DSTATCOM with configuration1 
- Configuration2 of system with DSTATCOM using rectifier on load side is presented in Figure 2 and implemented for power quality improvement with proposed I $\cos \phi$ technique for PFC mode of DSTATCOM operation for harmonic suppression, compensation of reactive power, load balancing and voltage regulation.

- Configuration3 of system with DSTATCOM using DC voltage source is presented in Figure 3 and implemented for power quality improvement with proposed I $\cos \phi$ technique for PFC mode of DSTATCOM operation for harmonic suppression, reactive power compensation, load balancing and voltage regulation.

Non-linear load with has been selected for all above system configurations under dynamic condition.

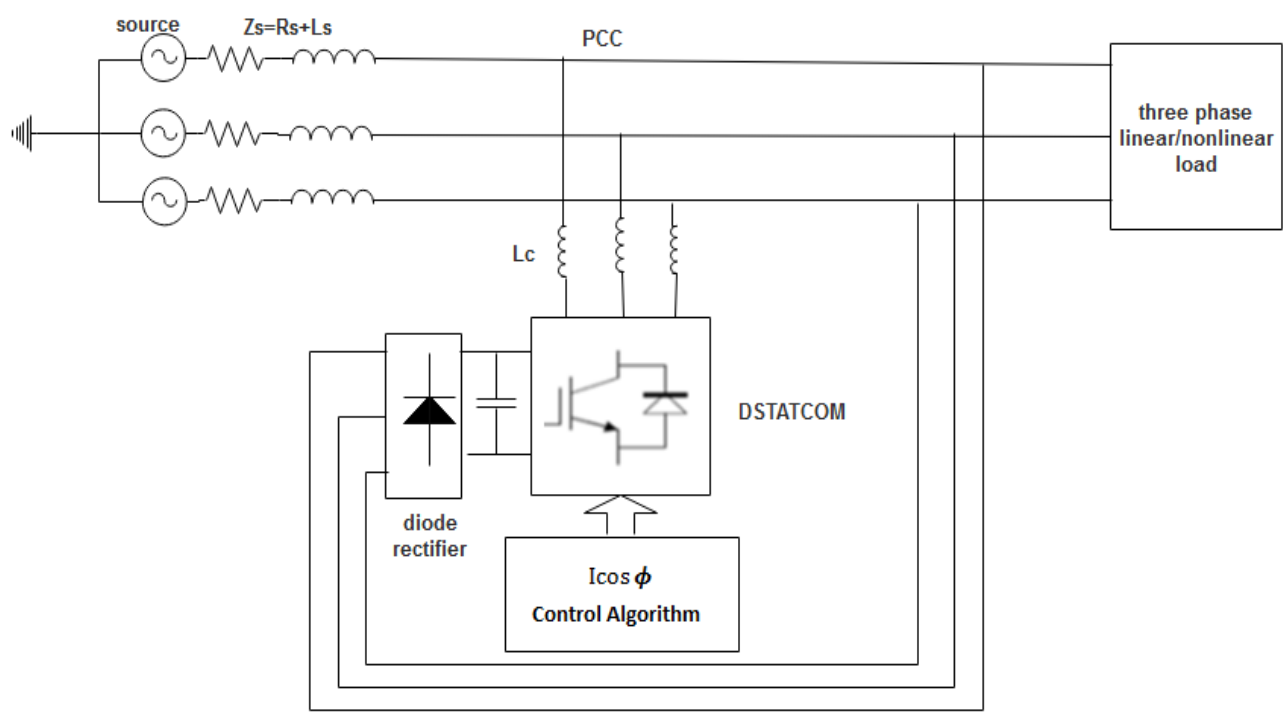

Figure 2. DSTATCOM with configuration2

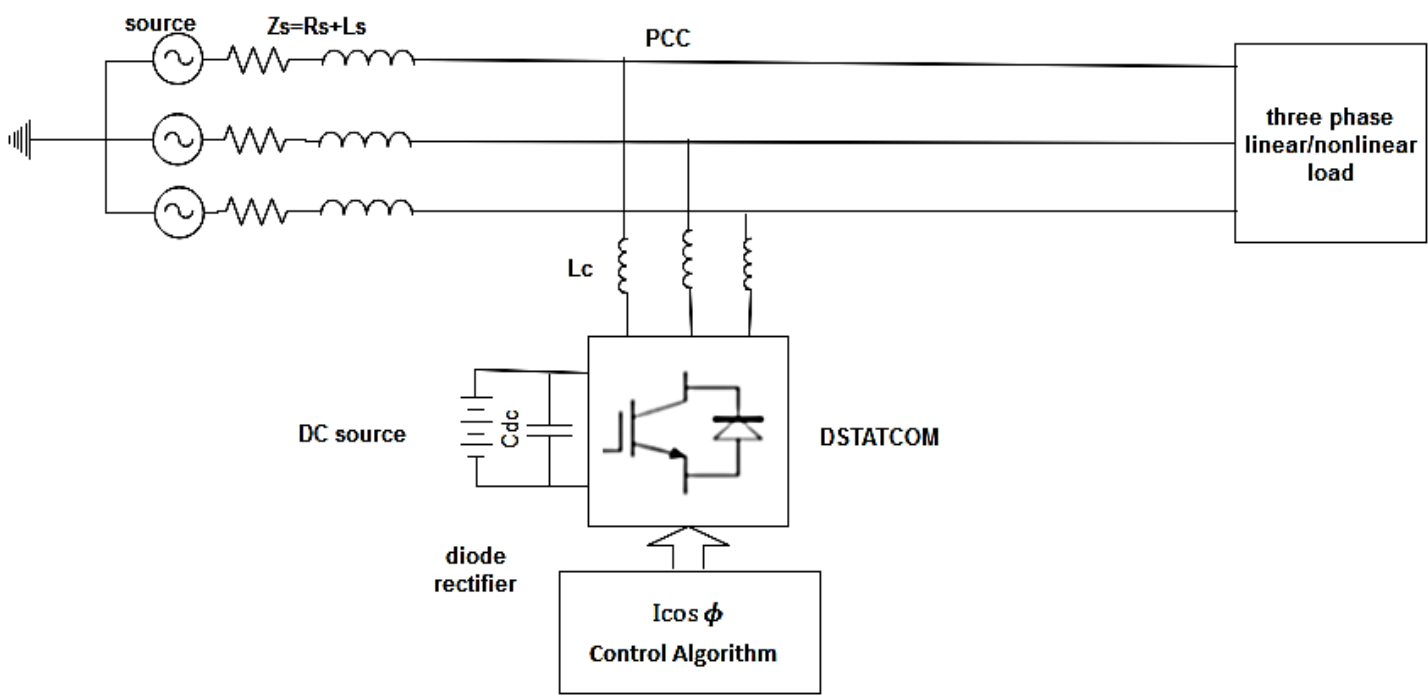

Figure 3. DSTATCOM with configuration3

\section{PROPOSED CONTROL METHOD}

The proposed I $\cos \phi$ is shown in Figure 4. The coupling point voltages $\left(V_{s a}, V_{s b}, V_{s c}\right)$, source currents $\left(i_{s a}, i_{s b}, i_{s c}\right)$, load current $\left(i_{L a}, i_{L b}, i_{L c}\right)$, and $V_{d c}$ DC output voltage of DSTATCOM are used as feedback signal for controller design. Supply reference currents are extracted with the help of these signals. 
Here it is assumed that using Icos $\phi$ technique only active power components of load current are supplied by source. Where I and $\phi$ represents the ampilude of essential load current and displacement angle w.r.t. PCC voltage. For estimation of supply reference current, I $\cos \phi$ and Isin $\phi$ component of load currents are multiplied unit templates of coupling point voltage. The instantaneous value load currents are given by,

$$
\begin{aligned}
i_{L a} & =\sum_{n=1}^{\infty} I_{L a n} \sin \left(n \omega t-\phi_{a n}\right) \\
i_{L b} & =\sum_{n=1}^{\infty} I_{L b n} \sin \left(n \omega t-\phi_{b n}-120^{\circ}\right) \\
i_{L c} & =\sum_{n=1}^{\infty} I_{L c n} \sin \left(n \omega t-\phi_{c n}-240^{\circ}\right)
\end{aligned}
$$

where

$\phi_{a}, \phi_{b}$ and $\phi_{c}$ are phase's angle for a, b and c phase respectively of essential component of load currents. $\phi_{a n}, \phi_{b n}, \phi_{c n}$ are the phase angle for a, b , c phase respectively of nth harmonic current.

$i_{L a}, i_{L b}, i_{L c}$ are the amplitude for $\mathrm{a}, \mathrm{b}, \mathrm{c}$ phase respectively of load current fundamental component.

$I_{L a n}, I_{L b n}$ and $I_{L c n}$ are the amplitude for $\mathrm{a}, \mathrm{b}$ and $\mathrm{c}$ phase respectivelyof load current $\mathrm{nth}$ harmonic current component.

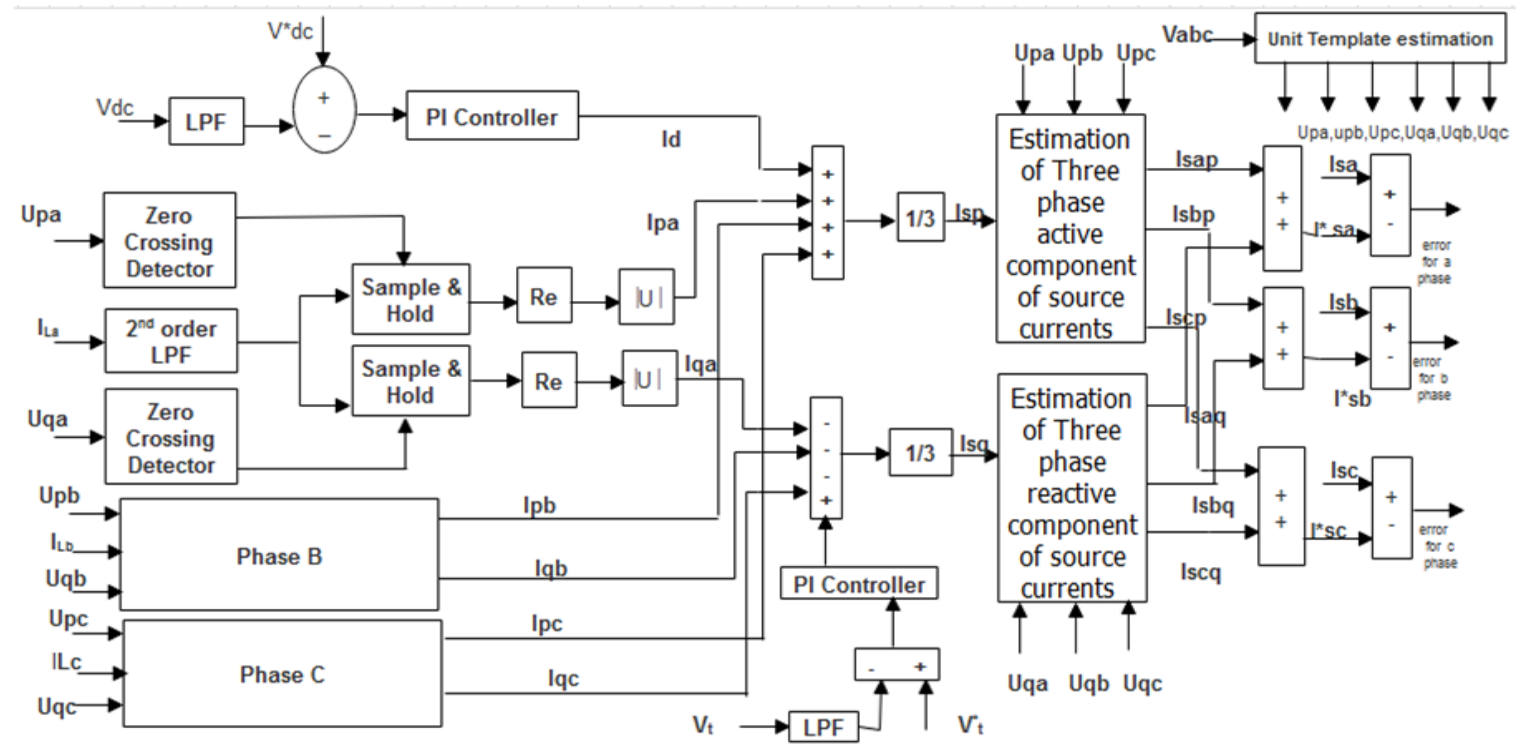

Figure 4. Proposed I $\cos \phi$ method

Amplitude of essential active load current components is recognized as (4).

$$
\left|\operatorname{ReI}_{L a 1}\right|=\left|I_{L a}\right| \cos \phi_{a},\left|\operatorname{ReI}_{L b 1}\right|=\left|I_{L b}\right| \cos \phi_{b},\left|\operatorname{Re} I_{L c 1}\right|=\left|I_{L c}\right| \cos \phi_{c}
$$

The magnitude I $\cos \phi$ of essential active component of load current is computed at zero crossing of in-phase templates of coupling point voltage by shifting the load current via $90^{\circ}$ from load current, through low power filter sets. Filters having cut of frequency $50 \mathrm{~Hz}$ are used to abstract essential load current. Zero crossing detector (ZCD) and a sample and hold circuit (SHC) are used for extraction of Icos $\phi$. Reference source current active component average value magnitude is given by (5),

$$
I_{s p}=\frac{\left(\left|I_{L a}\right| \cos \phi_{a}+\left|I_{L b}\right| \cos \phi_{b}+\left|I_{L c}\right| \cos \phi_{C}+I d\right)}{3}
$$

where $\left|I_{L a}\right| \cos \phi_{a},\left|I_{L b}\right| \cos \phi_{b}$ and $\left|I_{L c}\right| \cos \phi_{c}$ are the amplitude of active component fora, $\mathrm{b}$ and $\mathrm{c}$ phase respectively. $I_{d}$. Output current of DC PI controller of DSTATCOM and written as (6),

$$
I_{d}=K_{p d c} V_{d c e}+K_{I d c} \int V_{d c} d t
$$

where $V_{d c e}=V_{d c}^{*}-V_{d c}=$ error signal, $V_{d c}=$ output of DSTATCOM, $V_{d c}^{*}=$ Reference DC voltage. $K_{p d c}$ and $K_{I d c}$ are gains for DC PI controller. 
In same way the amplitude $I \sin \phi$ of essential load current reactive component is computed at zero crossing of quadrature template of coupling point voltage, from filtered essential load current. Avearage value of reference source current reactive component is given by (7),

$$
I_{s d}=\frac{\left(-\left(\left|I_{L a}\right| \sin \phi_{a}+\left|I_{L b}\right| \sin \phi_{b}+\left|I_{L c}\right| \sin \phi_{C}\right)+I_{a}\right)}{3}
$$

where $\left|I_{L a}\right| \sin \phi_{a},\left|I_{L b}\right| \sin \phi_{b}$ and $\left|I_{L c}\right| \sin \phi_{c}$ are amplitude of reactive component a, b and c phase respectively. Output current of AC PI controller $I_{a}$ is expressed as (8),

$$
I_{a}=K_{p a c} V_{d a c}+K_{I a c} \int V_{d a c} d t
$$

where $V_{d a c}=V_{a c}^{*}-V_{a c}=$ coupling point voltage error signal, $V_{a c}^{*}=$ coupling point voltage reference value, $V_{a c}=$ coupling point actual voltage. $K_{p a c}$ and $K_{I a c}$, are gains for AC-PI controller. by (9).

Source current active component for each phase can be achieved using in phase templates and given

$$
I_{s a p}=I_{s p} U_{p a}, I_{s b p}=I_{s p} U_{p b}, I_{s c p}=I_{s p} U_{p c}
$$

Source current reactive component for each phase can be achieved using quadrature templates and given by (10).

$$
I_{s a q}=I_{s d} U_{q a}, I_{s b q}=I_{s d} U_{q b}, I_{s c q}=I_{s d} U_{q c}
$$

Reference total source currents $\left(\mathrm{I}_{\mathrm{sa}}^{*}, I_{S b}^{*}\right.$ and $\left.I_{S C}^{*}\right)$ are calculated with addition ofrespective active and reactive phase component.

$$
I_{s a}^{*}=I_{s a p}+I_{s a q}, I_{s b}^{*}=I_{s b p}+I_{s b q}, I_{s c}^{*}=I_{s c p}+I_{s c q}
$$

By subtracting of these currents $\left(\mathrm{I}_{\mathrm{sa}}^{*}, I_{s b}^{*}\right.$ and $\left.I_{s c}^{*}\right)$ from source currents $\left(i_{s a}, i_{s b}\right.$ and $\left.i_{s c}\right)$ and an error signal for each leg of VSC are extracted. Error signal are supplied to hysteresis current controller (HCC). HCC produces the pulses with the help of theses error signals for insulated gate bipolar transistor (IGBT) based DSTATCOM.

\section{RESULTS AND DISCUSSION}

Three different system configurations are implemented with DSTATCOM in MATLAB/Simulink. Then proposed I $\cos \phi$ method is used for control of DSTATCOM for enhancement of power quality, under dynamic condition, with non-linear load in distribution system. The performance of DSTATCOM with proposed controller is analyzed in time domain in three different system configuration.

\subsection{DSTATCOM performance in PFC mode}

Three system configurations performance with DSTATCOM is simulated in time domain analysis for $1.0 \mathrm{~s}$. Following analysis is prepared based on simulation results. Figure 5 shows the DSTATCOM performance for configuration 1of system in PFC mode for nonlinear load with varying load of phase ' $a$ ' for time $0.6-0.7 \mathrm{~s}$ and expressed in terms of coupling point voltage $\left(\mathrm{V}_{s a b c}\right)$, supply current $\left(I_{s a b c}\right)$ load current $\left(i_{L a b c}\right)$ and inverter current $\left(i_{c a b c}\right)$ respectively. Source current is balanced and sinusoidal, load and inverter currents are unbalanced and non-sinusoidal. Figure 6 shows the $V_{d c}$ dc link voltage of DSTATCOM is continuously increased before DSTATCOM is switched on and attain a value of $600 \mathrm{~V}$ and after the switch on of DSTATCOM it increased to $825 \mathrm{~V}$ and finally it becomes constant $700 \mathrm{~V}$ at $\mathrm{t}=0.3$ second. Figure 7 shows the DSTATCOM performance for configuration2 of system in PFC mode for nonlinear load with varying load of phase a for time $0.6-0.7 \mathrm{~s}$ and expressed in terms of coupling point voltage $\left(\mathrm{V}_{\text {sabc }}\right)$, supply current $\left(I_{s a b c}\right)$ load current $\left(i_{L a b c}\right)$ and inverter current $\left(i_{c a b c}\right)$ respectively. Source current is balanced and sinusoidal, load and inverter currents are unbalanced and non-sinusoidal. Figure 8 shows the $V_{d c} \mathrm{dc}$ link voltage of DSTATCOM is continuously increased before DSTATCOM is switched on and attain a value of $600 \mathrm{~V}$ and after the switch on of DSTATCOM it increased to $810 \mathrm{~V}$ and finally it becomes constant $700 \mathrm{~V}$ at $\mathrm{t}=0.27$ second. Figure 9 shows the DSTATCOM performance for configuration 3 of system in PFC mode for nonlinear load with varying load of phase a for time $0.6-0.7 \mathrm{~s}$ and expressed in terms of coupling point voltage $\left(\mathrm{V}_{s a b c}\right)$, supply current $\left(I_{s a b c}\right)$ load current $\left(i_{L a b c}\right)$ and inverter current $\left(i_{c a b c}\right)$ respectively. Source current is balanced and sinusoidal, load and inverter currents are unbalanced and non-sinusoidal. Figure 10 shows $V_{d c}$ DC link voltage of DSTATCOM 700V constant. 
Figures 11(a)-(c) (see Appendix) shows the configuration1 harmonic spectrum of source current with modified I $\cos \phi$, source current with existing I $\cos \phi$ and load current for phase ' $a$ ' are 3.13\%, 3.78\%, 27.31\% respectively. Figures 11(d)-(f) (see Appendix) shows the configuration2 harmonic spectrum of source current with modified I $\cos \phi$, source current with existing I $\cos \phi$ and load current of phase 'a' are $3.07 \%$, 3.22\%, 27.10\% respectively. Figures 11(g)-(i) (see Appendix) shows the configuration3 harmonic spectrum of source current with modified I $\cos \phi$, source current with existing I $\cos \phi$ and load current for phase ' $a$ ' are $0.53 \%, 2.02 \%, 27.74 \%$ respectively. Comparison of THD spectrum of modified Icos $\phi$ technique with existing I $\cos \phi$ for different system configuration of the system is shown in Table 1.THD \% for three different configuration are graphically presented in Figures 11(a)-(i) (see Appendix). The Table 1 shows the modified I $\cos \phi$ technique is better than existing I $\cos \phi$ technique.
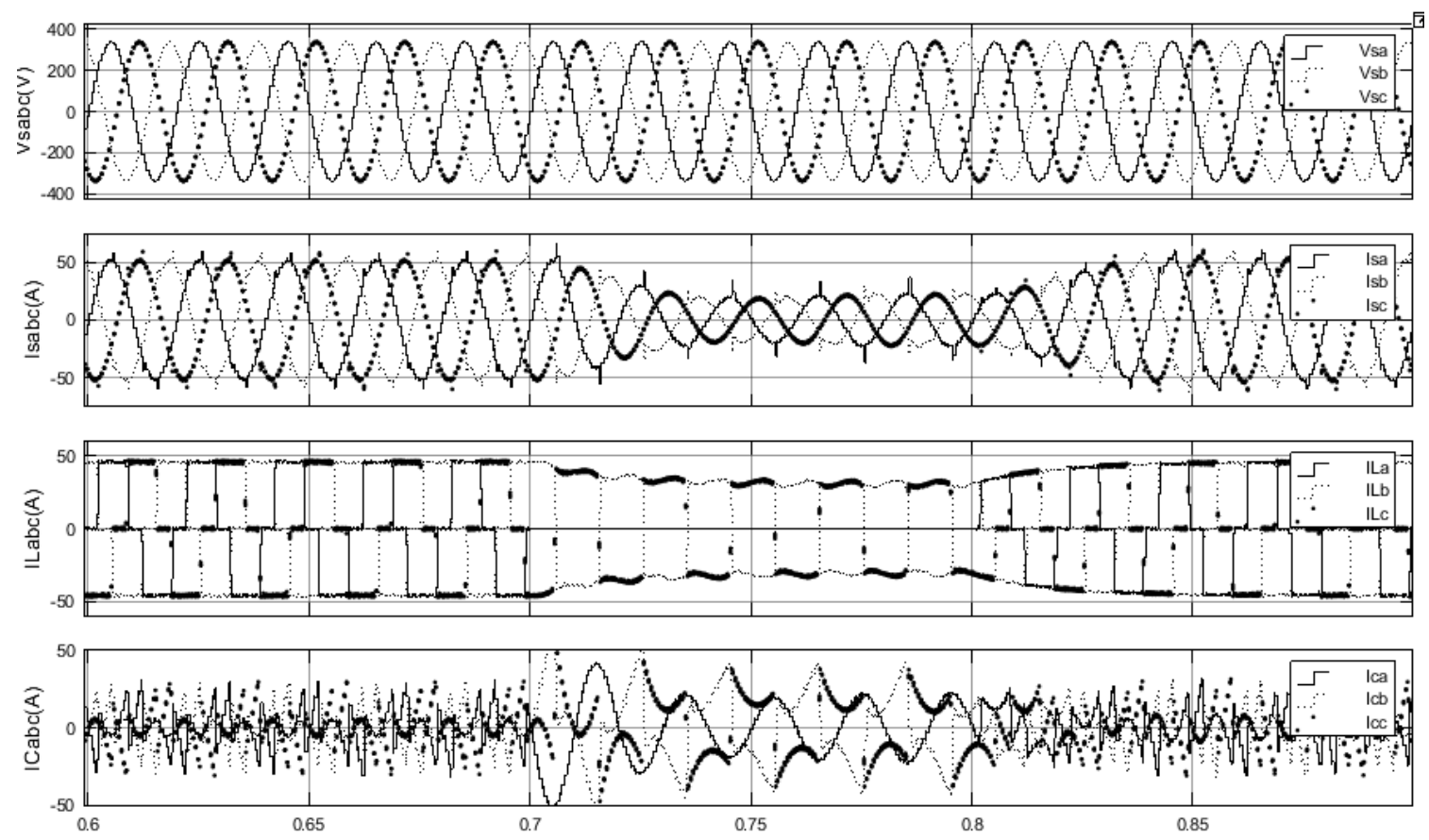

Figure 5. DSTATCOM performance for system configuration1

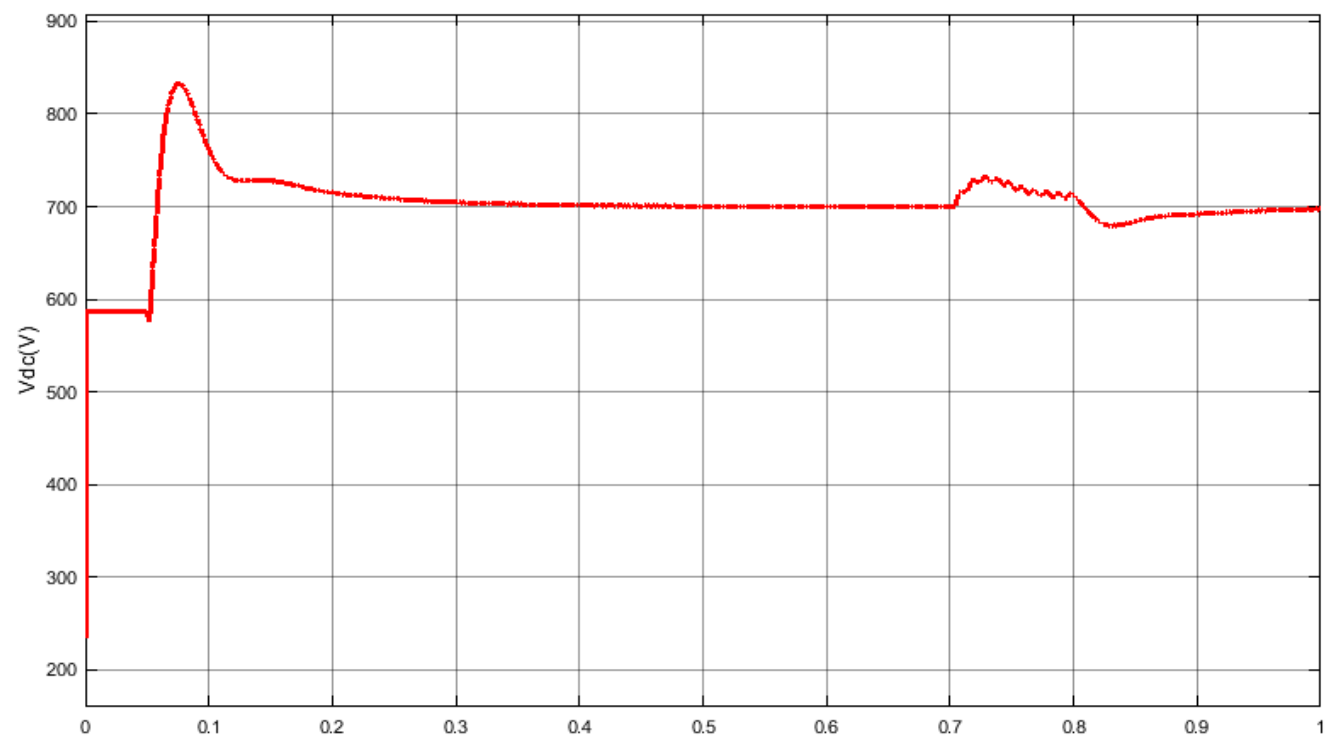

Figure 6. DC link voltage in PFC mode under variable nonlinear load for system configuration1 

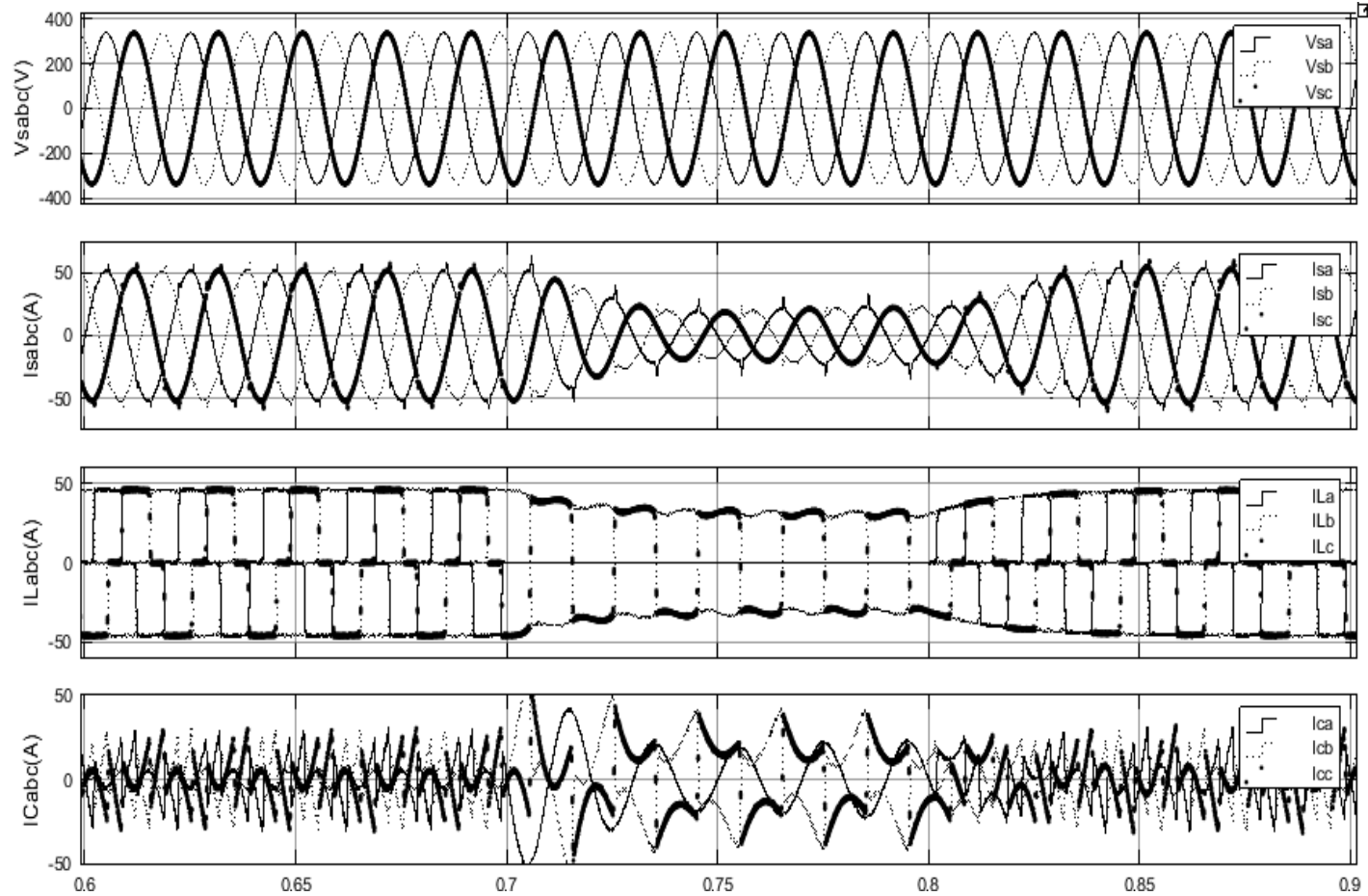

Figure 7. DSTATCOM performance for system configuration2

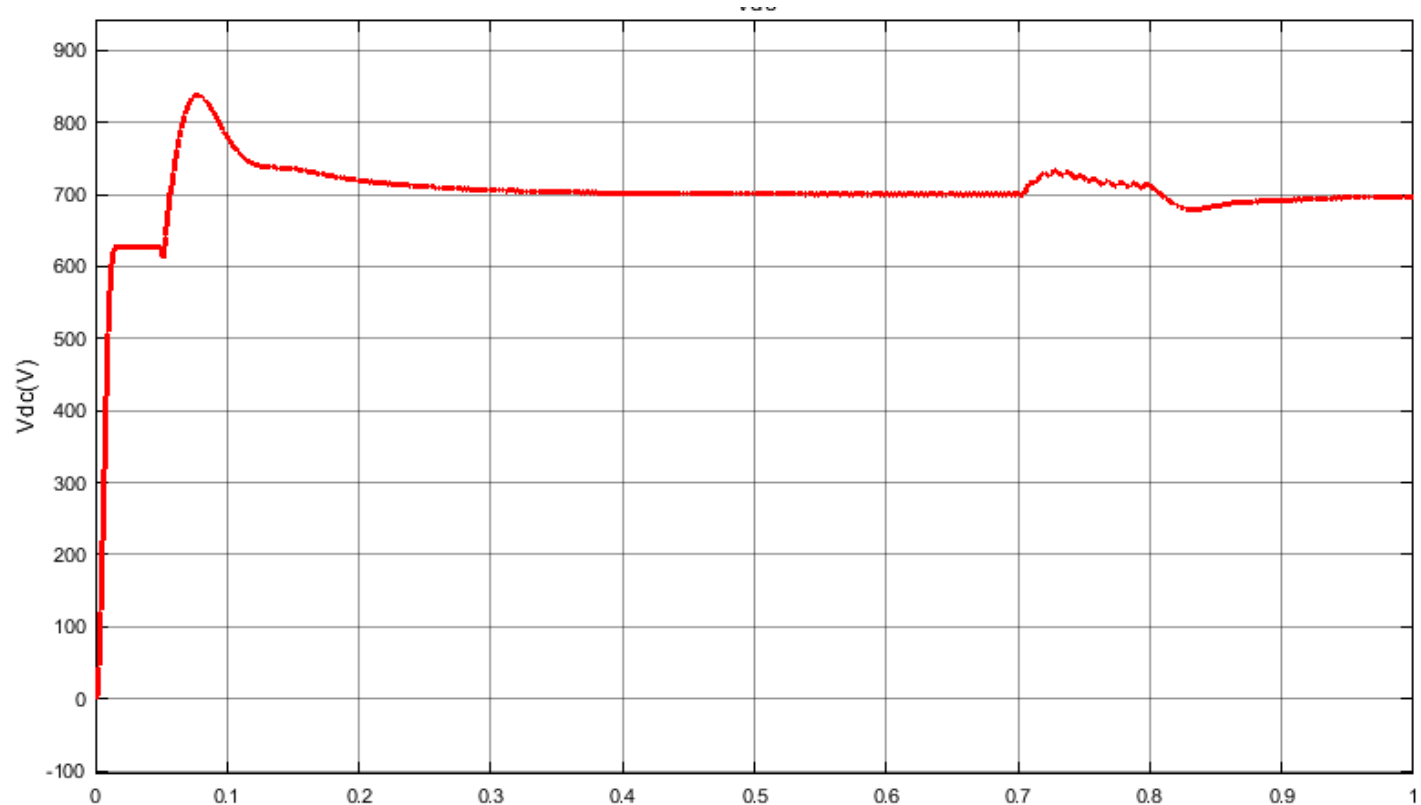

Figure 8. DC link voltage in PFC mode under variable nonlinear load for system configuration3

Table 1. The performance analysis for different system configurations

\begin{tabular}{|c|c|c|c|c|c|}
\hline \multirow[b]{2}{*}{ Sr.No. } & \multirow[b]{2}{*}{ System configuration type } & \multicolumn{2}{|c|}{ Source current harmonics } & \multirow{2}{*}{$\begin{array}{l}\text { Load current harmonics } \\
\text { Modified I } \cos \phi\end{array}$} & \multirow{2}{*}{$\begin{array}{c}\text { DC link voltage settling time(s) } \\
\text { Modified Icos } \phi\end{array}$} \\
\hline & & Modified I $\cos \phi$ & Existing I $\cos \phi$ & & \\
\hline 1. & & $3.13 \%$ & $3.78 \%$ & $27.31 \%$ & 0.30 \\
\hline 2. & Configuration2 & $3.07 \%$ & $3.22 \%$ & $27.10 \%$ & 0.27 \\
\hline 3. & Configuration3 & $0.53 \%$ & $2.02 \%$ & $27.24 \%$ & 0 \\
\hline
\end{tabular}



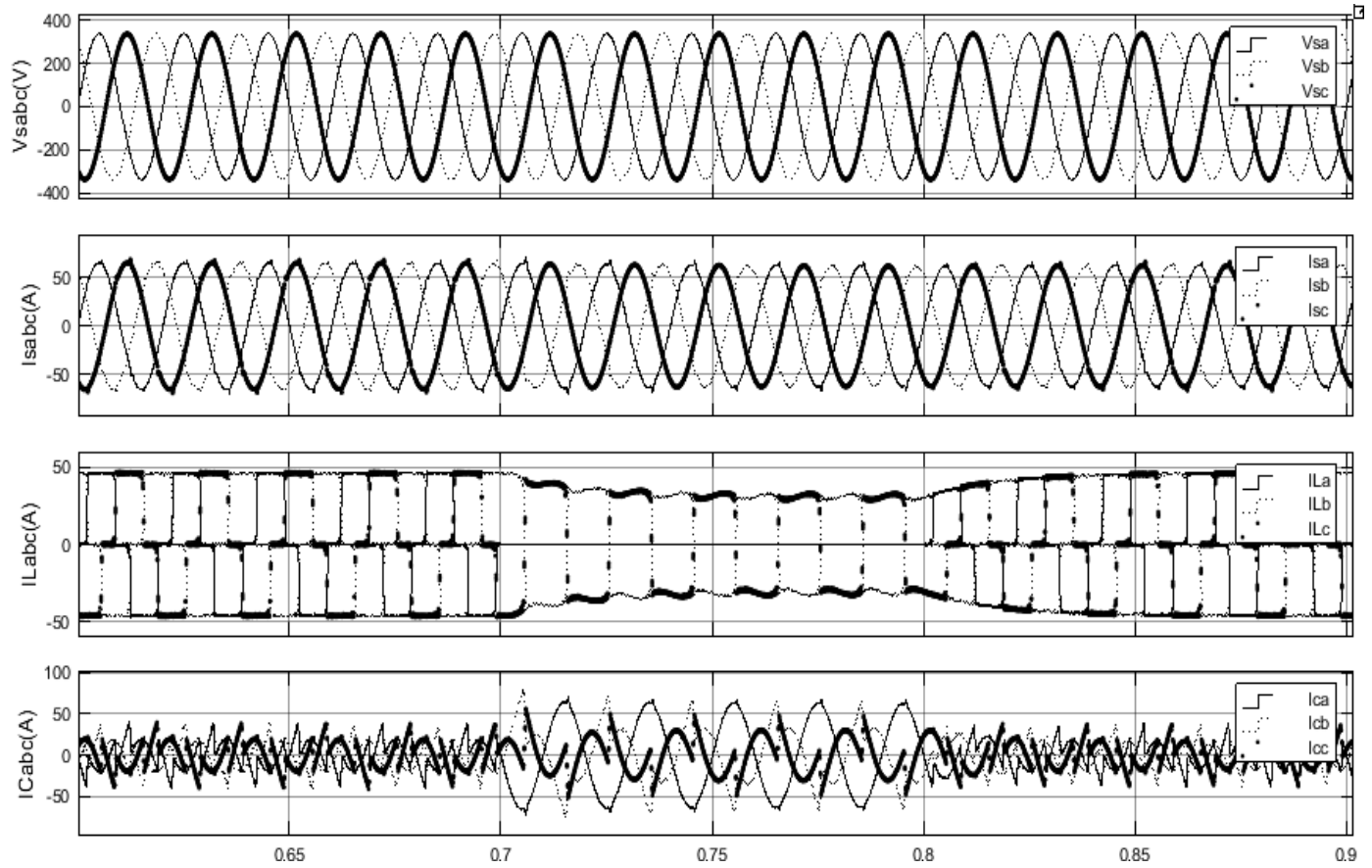

Figure 9. DSTATCOM performance for system configuration3

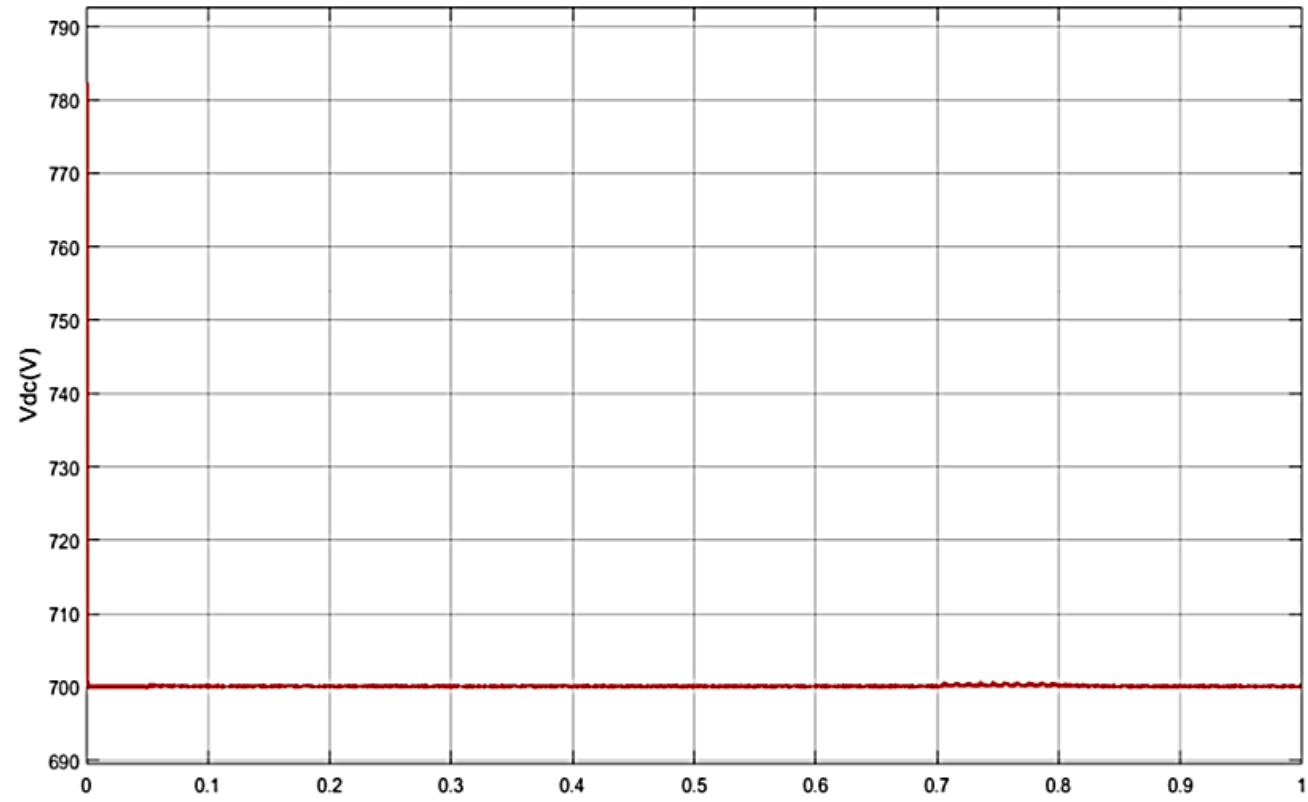

Figure 10. DC link voltage in PFC mode under variable nonlinear load for system configuration3

\section{CONCLUSION}

Three different systems configurations are simulated with DSTATCOM using proposed Icos $\phi$ in MATLAB/Simulink for DSTATCOM operation in PFC mode. For all three systems configuration DC link voltage of DSTATCOM is controlled in varying nonlinear load. The behavior of DSTATCOM with proposed I $\cos \phi$ is found very effective for different systems configuration in terms of harmonic elimination of source current, load balancing and power factor correction. The modified Icos $\phi$ technique is found better than existing I $\cos \phi$ in term of THD elimination of source current. These models can be used for teaching and research purpose for study the different types of power quality problems and also other configurations of system can be developed with DSTATCOM which are not considered in this paper. 


\section{APPENDIX}
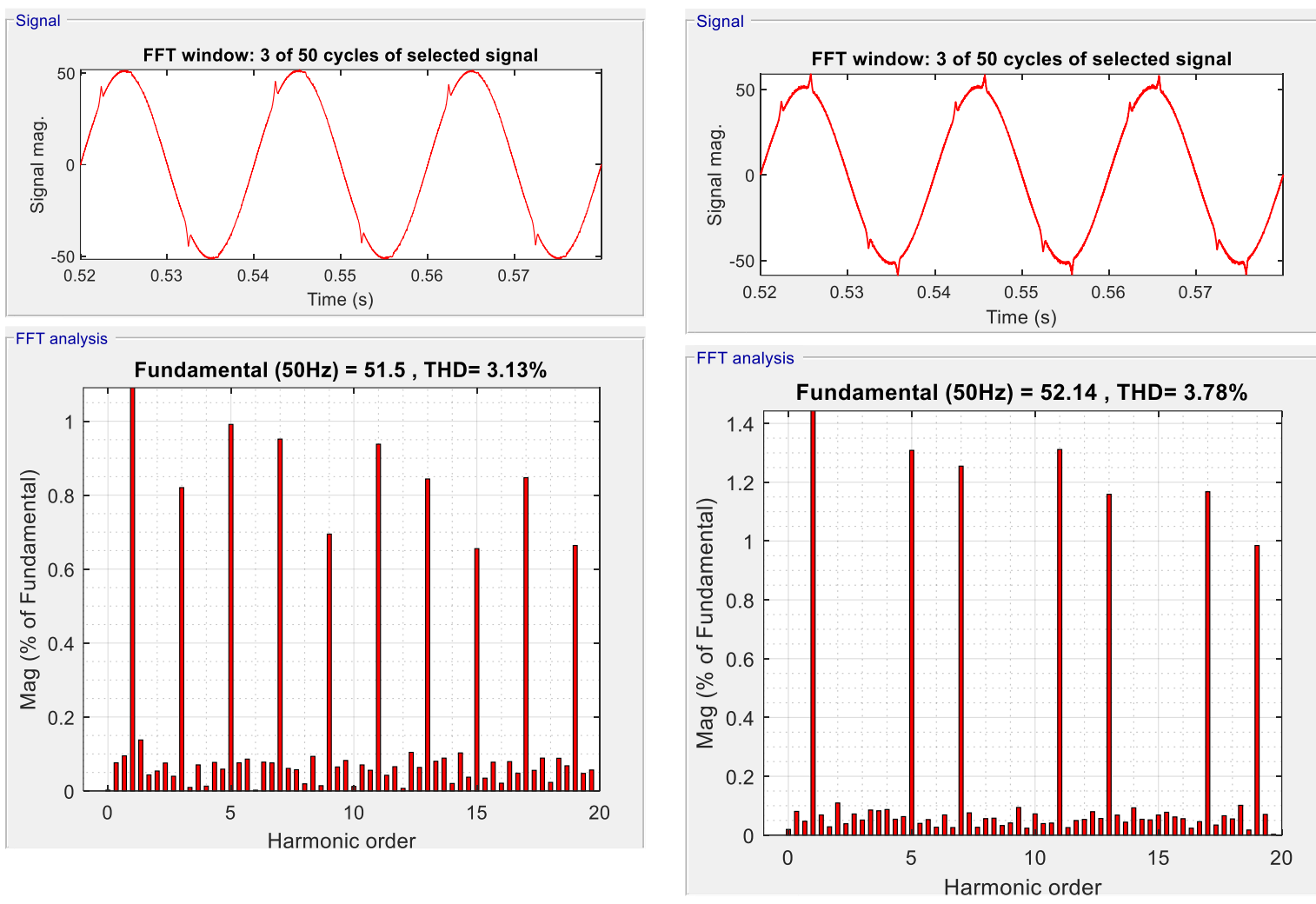

(a)

(b)
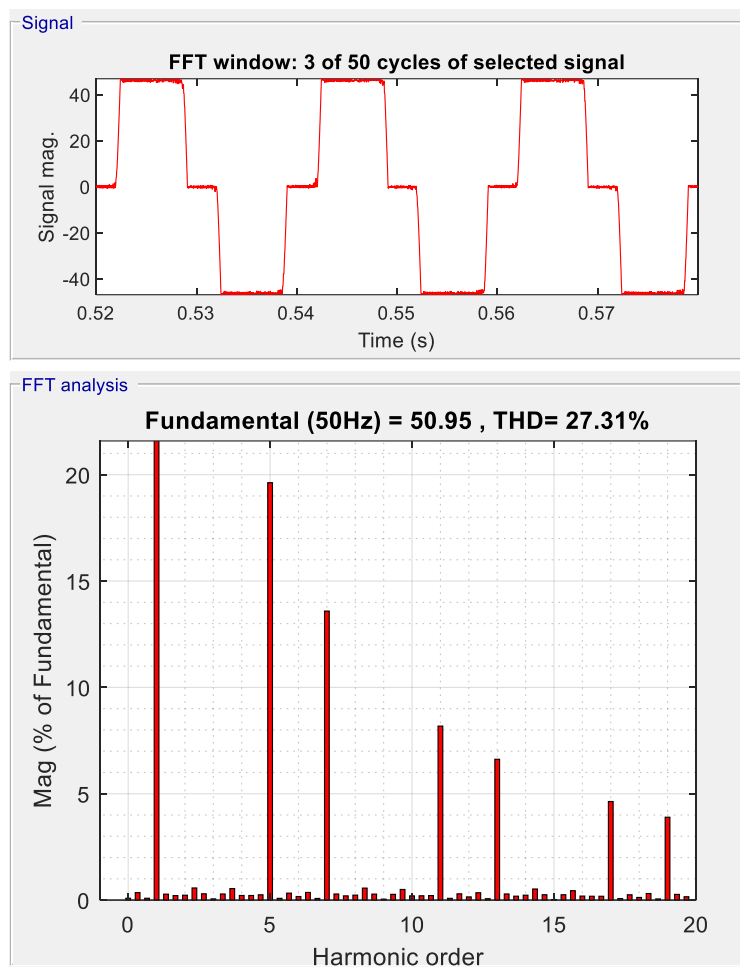

(c)

Figure 11. (a)-(c) shows the harmonic spectrum of source current with modified Icos $\phi$, source current with existing I $\cos \phi$ and load current for phase 'a' respectively for configuration1 

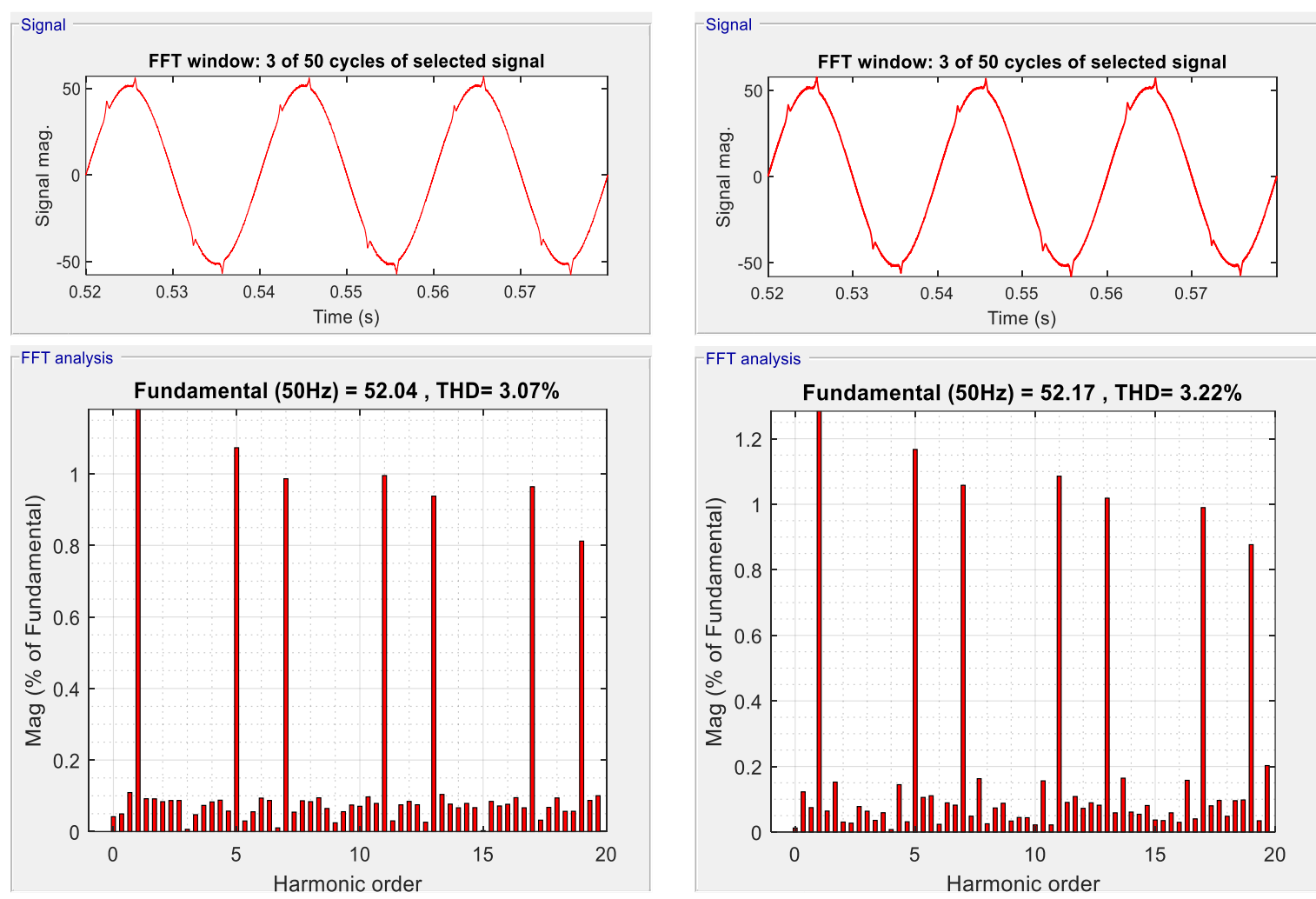

(d)

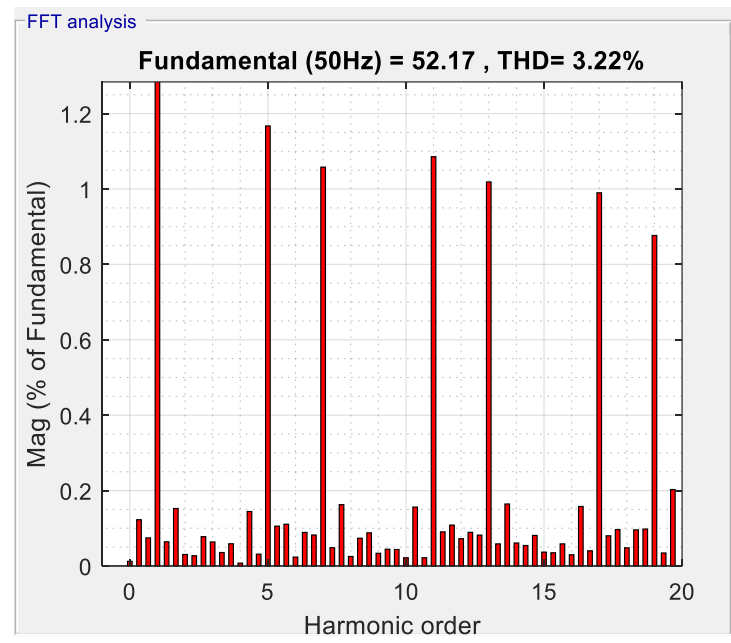

(e)
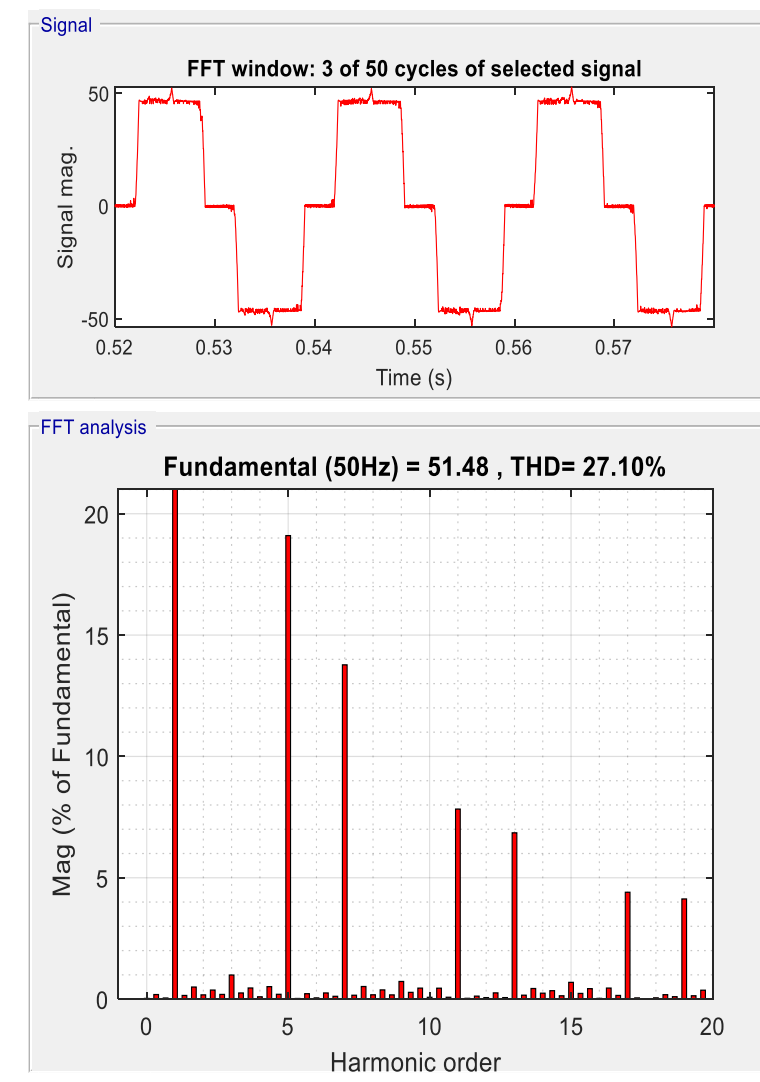

(f)

Figure 11. (d)-(f) shows the harmonic spectrum of source current with modified Icos $\phi$, source current with existing I $\cos \phi$ and load current for phase 'a' respectively for configuration2 (continue) 

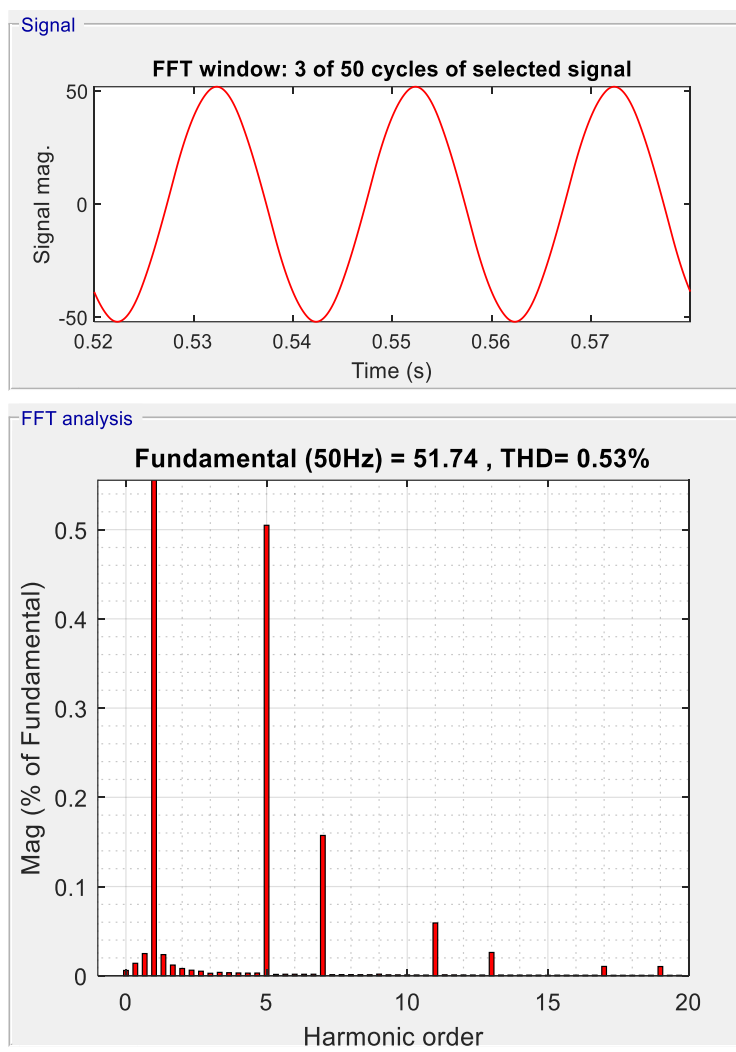

$(\mathrm{g})$
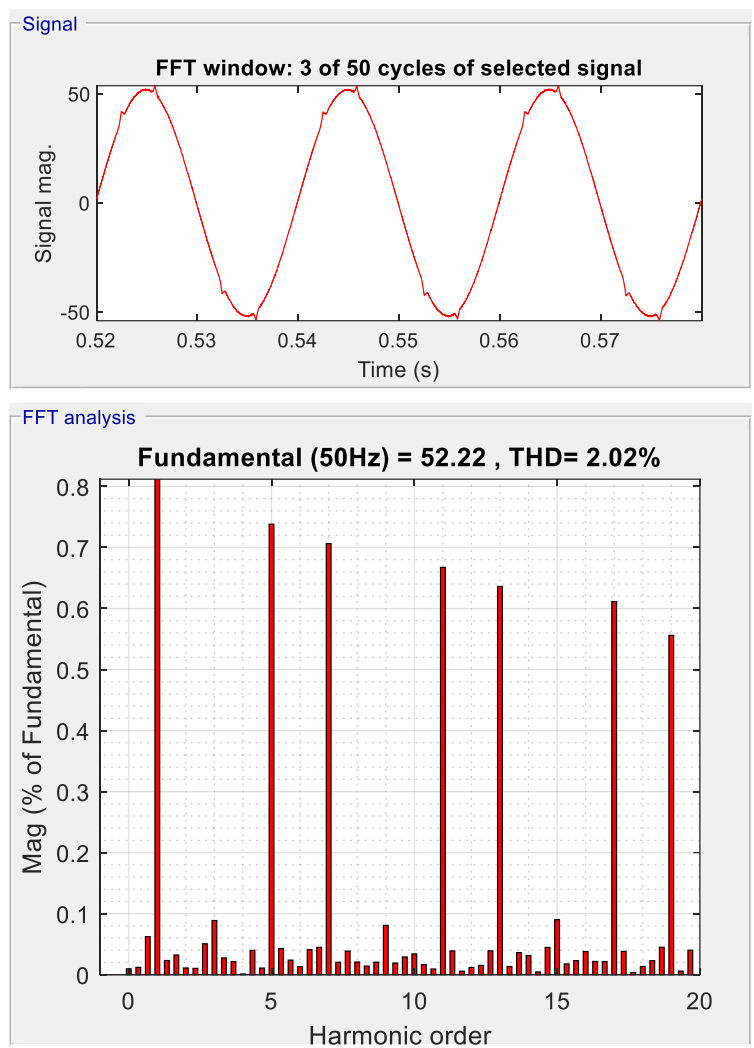

(h)
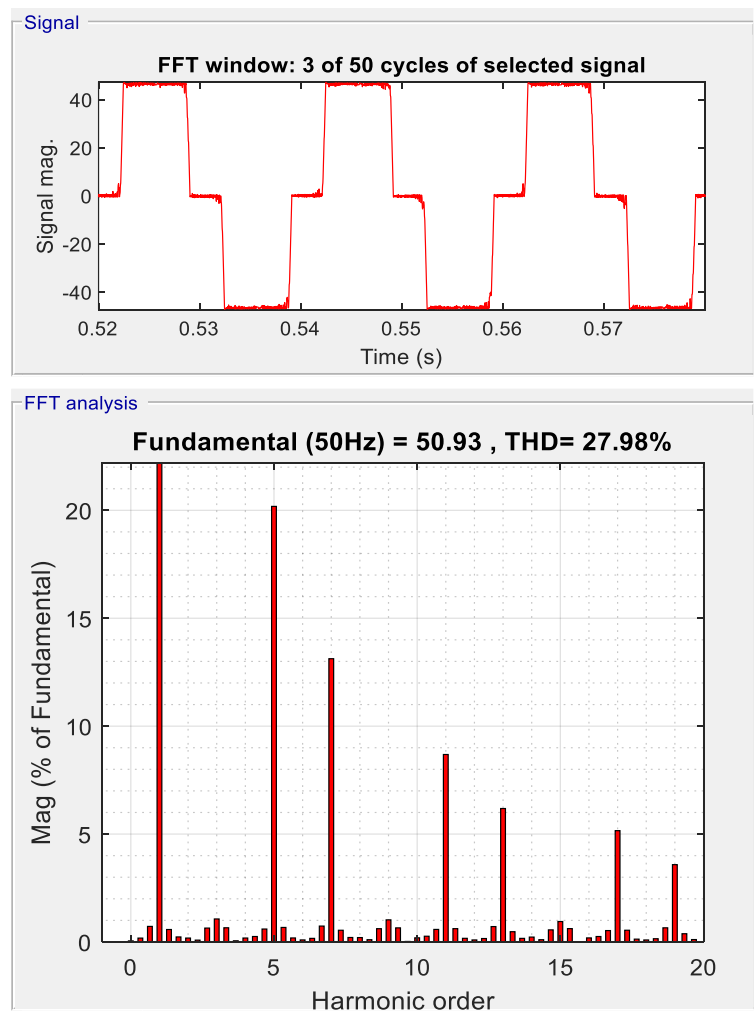

(i)

Figure 11. (g)-(i) shows the harmonic spectrum of source current with modified Icos $\phi$, source current with existing I $\cos \phi$ and load current for phase 'a' respectively for configuration3 (continue) 


\section{REFERENCES}

[1] Angelo Baggini, “Handbook on power quality,” John Wiley \& Sons, New Jersey, USA, 2008

[2] K. R. Padiyar, "FACTS Controllers in Power Transmission and Distribution," New Age International (P) Limited, Publishers, New Delhi, 2007.

[3] H. Akagi, E. H. Watanable, and M. Aredes, "Instantaneous power theory and application to power conditioning," Jhon Wiley \& sons, New Jersey, USA, 2007.

[4] A. M. Munoz, "Power Quality: Mitigation Technologies in Distributed Environment," Springer-Verlag London limited, London, 2007.

[5] B. Singh, P. Jayaprakash, and D. P. Kothari, "Three-phase four-wire dstatcom with H-bridge VSC and star/delta transformer for power quality improvement," in Proc. of INDICON 2008, vol. 2, Dec. 2008, pp. 412-417, doi: 10.1109/INDCON.2008.4768759.

[6] H.-Liahng, K..-D. Wu, J.-C. Wu, and W.- J. Chiang, "A three-phase four- wire power filter comprising a three phase three-wire active filter and a zig-zag transformer," IEEE Trans. On Power Electronics, vol. 23, no. 1, pp. 252- 259, Jan. 2008, doi: 10.1109/TPEL.2007.911779.

[7] S. Choi and M. Jang, "Analysis and Control of a Single-Phase-Inverter-Zigzag-Transformer Hybrid Neutral-Current Suppressor in Three-Phase Four-Wire Systems," IEEE Trans. on Industrial Electronics, vol. 54, pp. 2201-2208, Aug. 2007, doi: 10.1109/TIE.2007.899831

[8] F. N. Belchior, J. F. V. Ferreira, J. C. Oliveira, R. Apolonio, and A. B. Vasconcellos, "Three-phase electromagnetic filter for zerosequence harmonics," IEEE Trans. on Magnetics, vol. 42, pp. 2201-2207, Sept. 2006, doi: 10.1109/ICHQP.2004.1409423.

[9] B. Singh, P. Jayaprakash, T. R. Somayajulu, D. P. Kothari, A. Chandra, and K. Al-Haddad, "Integrated three-leg VSC with a zigzagtransformer based three-phase four-wire DSTATCOM for power quality improvement," in Proc. of IECON 2008, pp. 796 -80, Nov. 2008, doi: 10.1109/IECON.2008.4758055.

[10] H.- L. Jou, J.- C. Wu, K.- D. Wu, W.- J. Chiang, and Y.- H. Chen, "Analysis of zig-zag Transformer applying in the three-phase Four-Wire Distribution Power System," IEEETrans. on Power Delivery, vol. 20, no. 2, pp.1168- 1173, April 2005, doi: 10.1109/TPWRD.2005.844281.

[11] G. Bhuvaneswari, M. G. Nair, and S. K. Reddy, "Comparison of Synchronous Detection and Icos $\Phi$ Shunt Active Filtering Algorithms," Conf. IEEE PEDES '06. , pp. 1-5, Dec. 2006, doi: 10.1109/PEDES.2006.344229.

[12] G. Bhuvaneswari and M. G. Nair, "Design, Simulation, and Analog Circuit Implementation of a Three-Phase Shunt Active Filter Using the Algorithm," IEEE Trans. on Power Delivery, vol. 23, pp. 1222-1235, April 2008, doi: 10.1109/TPWRD.2007.908789.

[13] G. Bhuvaneswari and M. G. Nair, "Design, Simulation and Analog Circuit Implementation of a Three-phase Shunt Active Filter

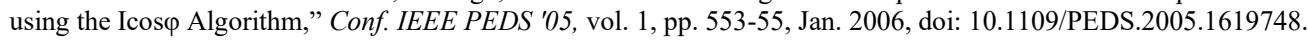

[14] B. Singh and S. Kumar, "Control of DSTATCOM using IcosФ Algorithm," 2009 35th Annual Conference of IEEE Industrial Electronics, pp. 322-327, IEEE, doi: 10.1109/IECON.2009.5414942.

[15] P. Kumar, N. Kumar, and A. K. Akella, "Modeling and Simulation of Different System Topologies for DSTATCOM," AASRI Conference on Parallel and Distributed Computing and Systems, pp. 249-256, Dec. 2013, doi: 10.1016/j.aasri.2013.10.086.

[16] B. Singh, S. K. Dube and S. R. Arya, "An improved control algorithm of DSTATCOM for power quality improvement," Electrical Power and Energy Systems, vol. 64, pp. 493-504, 2015, doi: 10.1016/j.ijepes.2014.07.055.

[17] B. Singh, P. Jayaprakash, D. P. Kothari, A. Chandra, and K. Al Haddad, "Comprehensive Study of DSTATCOM Configurations," IEEE Transactions ON Industrial Informatics, vol. 10, no. 2, May 2014, doi: 10.1109/TII.2014.2308437.

[18] S. K. Patel, S. R. Arya, and R. Maurya, "Optimal Step LMS-Based Control Algorithm for DSTATCOM," Distribution System. Electric Power Components and Systems, pp. 1-17, 2019, doi: 10.1080/15325008.2019.1602797.

[19] M. Mangaraj and A. K. Panda, "DSTATCOM deploying CGBP based Icos $\phi$ neural network technique for power conditioning," Ain Shams Engineering Journal, vol. 9, no. 4, pp. 1335-1346, 2016, doi: 10.1016/j.asej.2016.11.009.

[20] A. Jain and M. Jain "Comparison of Star/Delta and Zig/Zag Transformer Based DSTATCOM for Power Quality Improvement," 2016 IEEE Students' Conference on Electrical, Electronics and Computer Science, 978-1-4673-7918-2/16/\$31.00 O2016 IEEE, doi: 10.1109/SCEECS.2016.7509289.

[21] A. K. Panda, T. Penthia, M. Mangaraj, and A. R. Dash, "Power quality refinement by executing icos $\Theta$ Control Algorithm in Fuel Cell based DSTATCOM," 2018 IEEMA Engineer Infinite Conference (eTechNxT), 2018, pp. 1-6, doi: 10.1109/ETECHNXT.2018.8385299.

[22] R. Pulikkal and K. Rathi, "PV supported DSTATCOM using Icos $\Theta$ controller," 2015 International Conference on Power, Instrumentation, Control and Computing (PICC), 2015, pp. 1-5, doi: 10.1109/PICC.2015.7455753.

[23] S. R. Arya, M. M. Patel, S. J. Alam, J. Srikakolapu, and A. K. Giri, "Phase lock loop-based algorithms for DSTATCOM to mitigate load created power quality problems," Int Trans Electr Energ Syst.2019; e12161, doi: 10.1002/2050-7038.12161.

[24] A. K. Giri, S. R. Arya, R. Maurya, and B. C. Babu, "Mitigation of power quality problems in PMSG-based power generation system using quasi Newton-based algorithm," Int Trans Electr Energ Syst. 2019;e12102, doi: 10.1002/2050-7038.12102.

[25] S. K. Patel, S. R. Arya, and R. Maurya, "Optimal Step LMS-Based Control Algorithm for DSTATCOM in Distribution System," Electric Power Components and Systems, vol. 47, no. 8, pp. 1-17, 2019, doi: 10.1080/15325008.2019.1602797.

[26] M. Srinivas, I. Hussain, and B. Singh, "Combined LMS-LMF Based Control Algorithm of DSTATCOM for Power Quality Enhancement in Distribution System," IEEE Transactions on Industrial Electronic, vol. 63, no. 7, pp. 4160-4168, 2016, doi: 10.1109/TIE.2016.2532278

[27] Md. T. Ahmad, N. Kumar, and B. Singh, "AVSF-based control algorithm of DSTATCOMfor distribution system," IET Gener. Transm. Distrib., 2017, vol. 11 no. 13, pp. 3389-3396, doi: 10.1049/iet-gtd.2017.0225.

[28] P. Chittora, A. Singh, and M. Singh, "Application of Hopfield Neural Network for Harmonic Current Estimation and Shunt Compensation," Electric Power Components and Systems, vol. 46, no. 3, pp. 290-301, 2018. doi: $10.1080 / 15325008.2018 .1445794$

[29] S. Ray, N. Gupta, and R. A. Gupta, "Mathematical and Experimental Investigation on Advanced PLL for Cascaded H-Bridge Multilevel Inverter in Active Filtering Application," Electric Power Components and Systems, vol. 48, no. 7, pp. 1-17, 2019, doi: $10.1080 / 15325008.2019 .1582564$.

[30] T. Penthia, A. K. Panda, and M. Mangaraj, "Real-time simulation and performance of DSTATCOM using an improved load current detection-based control technique for compensation of current harmonics and load transients," Journal: European Power Electronics and Drives, Aug. 2020, doi: 10.1080/09398368.2020.1811572. 


\section{BIOGRAPHIES OF AUTHORS}

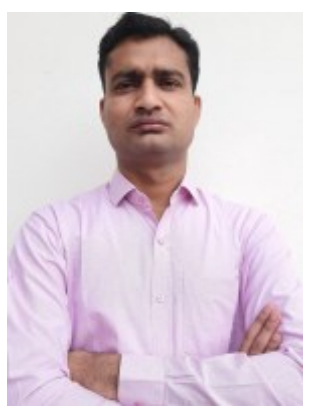

Atma Ram (D) 8. SC P born in 1985 in India and received his B. Tech degree From Kurukeshetra University in2007 in Electrical engineering and M.Tech degree from J. C. Bose University of Science and Technology, YMCA, (formerly YMCAUST) Faridabad (Haryana) in 2012 in Power System and Drives. He has currently working as Assistant professor in Electrical Engineering department and Pursuing Ph.D from J. C. Bose UST, YMCA, Faridabad. His research area is power system, power electronics and drives, renewal energy, active filters and power quality. He can be contacted at email: atma.ram12@gmail.com.

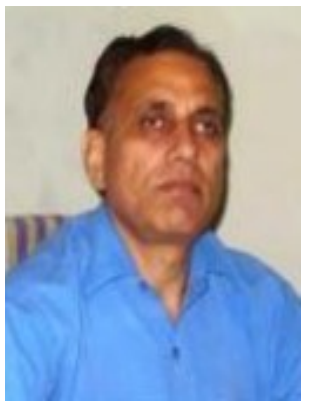

Parsh Ram Sharma (D) SC SC born in 1966 in India and received his B. Tech degree From REC Kurukeshetra 1988 in Electrical engineering and M. Tech degree from PEC, Chandigarh (Pujab) in 1992 in power system and drives and Ph.D in 2005 from MDU, Rohtak (Haryana). He has currently working as professor in Electrical Enginnering Department since 1996 joined as lecture and supervised a number of projects/thesis. He has also published more than 100 papers in reputed journals and IEEE conferences. His research area is power system, FACTS, renewal energy, active filters power electronics and drives, and power quality. He can be contacted at email: prsharma1966@gmail.com.

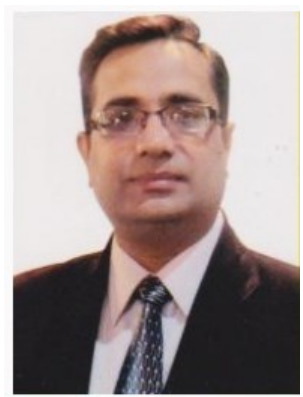

Rajesh Kumar Ahuja (D) I8 SC P has received his B.E from Nagpur University, M. Tech from IIT Khargpur and Ph.D from IIT Delhi in 2012. He has more than 20 years teaching experience and currently working as professor in Department of Electrical Engineering at J. C. Bose University of Science and Technology, YMCA, and Faridabad (Haryana), India. He has supervised a number of projects/thesis works in his area. He has published more than 50 papers in reputed journals and confernces few papers in international journals and IEEE conferences. His research area is power system, FACTS, renewal energy, active filters power electronics and drives, and power quality. He can be contacted at email: rajeshkrahuja@gmail.com. 